http://jmscr.igmpublication.org/home/ ISSN (e)-2347-176x ISSN (p) 2455-0450

crossref DOI: https://dx.doi.org/10.18535/jmscr/v8i10.11

Journal Of Medical Science And Clinical Research

IGM Publication

An official Publication of IGM Publication

\title{
A Cross sectional Study to access Knowledge of Tuberculosis in Healthcare Workers in Tertiary Care Hospital, India
}

\author{
Dr Manan Bedi ${ }^{*}$, Dr R.C. Meena ${ }^{2}$, Dr Nalin Joshi ${ }^{3}$, Dr P.R. Gupta ${ }^{4}$, Dr Manish Jain ${ }^{5}$, \\ Dr Prem Kumar ${ }^{6}$, Dr T.K Kublani ${ }^{7}$, Dr Pradeep Sudwal ${ }^{8}$, Dr Devender Sharma ${ }^{9}$, \\ Dr Kunal ${ }^{10}$ \\ ${ }^{1}$ Junior Resident, Department of Respiratory Medicine, NIMS \&R, Jaipur, Rajasthan \\ ${ }^{2}$ Professor and Head of Department, Department of Respiratory Medicine, NIMS \& R, Jaipur, Rajasthan \\ ${ }^{3,4}$ Professor, Department of Respiratory Medicine, NIMS \&R, Jaipur, Rajasthan \\ ${ }^{5,7,8}$ Assistant Professor, Department of Respiratory Medicine, NIMS \&R, Jaipur, Rajasthan \\ ${ }^{6}$ Associate Professor, Department of Respiratory Medicine, NIMS \&R, Jaipur, Rajasthan \\ *Corresponding Author \\ Dr Manan Bedi
}

\begin{abstract}
Introduction: Tuberculosis is a preventable and treatable disease but still is second most common cause of death among infectious diseases in India. But in a country like India, early diagnosis of active cases are still an area of difficulty. Early diagnosis and management by knowledgeable and skilled healthcare workers (HCWs) are key in addressing this health issue. Tuberculosis (TB) is a one major public health problem in India, thus assessment of knowledge is essential to plan, implement, and evaluate advocacy and may improve the case detection rate.
\end{abstract}

Material and Method: A cross-sectional study was conducted in National Institute of Medical Sciences and Research, Jaipur, Rajasthan, India. A questionnaire was given to 150 healthcare workers including 75 doctors, 50 nursing staff and 25 technicians. The responses were then analysed.

Result: The total number of respondents was 150, 75 were doctors, 50 were nursing staff and 25 were technician. Study population consisting of $66.66 \%$ male and $33.33 \%$ female. All participants were over 15 years old and more than half of them (65.32\%) were within 30-50 years. About $96 \%$ were residing in rural areas. Most of the patients belong to 30-49 years (38.66\%) with $35 \%$ males and $23 \%$ of female in this category. Among 150 healthcare workers, doctors were well aware of tuberculosis, but knowledge of nurses and technicians were slightly lacking. Although $90 \%$ and $80 \%$ of nursing staff and technicians respectively knew that pulmonary tuberculosis is contagious. $67.33 \%$ of healthcare workers were of rural area, out of which $88 \%$ are technicians and $98 \%$ are nursing staff. $60 \%$ of doctors belong to urban area.

Conclusion: In conclusion, after assessing data doctors are well aware of knowledge regarding tuberculosis, but nursing staff and technicians lack sufficient knowledge. They are still in need of continuing programs to educate them regarding control and prevention of this disease. Initiative should be taken in each and every hospital to start RNTCP sensitization program at regular intervals. Thus improved knowledge on tuberculosis of healthcare workers will contribute to better management of this disease and will help in long term plan to eradicate tuberculosis from India.

Keywords: Tuberculosis, knowledge, healthcare workers, infection, nursing staff, doctors, technicians. 


\section{Introduction}

Tuberculosis is a preventable and treatable disease but still is second most common cause of death among infectious diseases in India ${ }^{1}$. Early diagnosis of tuberculosis and prompt management leads to effective control of tuberculosis. But in a country like India, early diagnosis of active cases are still an area of difficulty. Early diagnosis and management by knowledgeable and skilled healthcare workers (HCWs) are key in addressing this health issue ${ }^{2}$.

The effectiveness of DOTS is determined by health-seeking behaviors of patient, which is related to patients' knowledge of TB, health education, demo- graphic characteristics, and traditional beliefs. These are important for treatment compliance and thus treatment success rate. $^{3,4}$

Various Studies done previously observed that knowledge score was low among the illiterate, females, rural residences, and youngest age group. Also, this disease had a significant impact on social relations when there is stigma, discrimination, and several misconceptions that contribute to poor adherence to treatment ${ }^{5,6,7}$

Tuberculosis (TB) is a one major public health problem in India, thus assessment of knowledge is essential to plan, implement, and evaluate advocacy and may improve the case detection rate.

There are very few studies in our country regarding assessing the knowledge and awareness and practice among healthcare workers. This study seeks to assess these parameters.

India contributes to one-fourth of world tuberculosis patients. Thus a study done by Acharya et $\mathrm{al}^{13}$ showed that adequate knowledge among doctors and nursing staff is a must to combat the burden of tuberculosis. Healthcare workers are the key population in every program for successful Tuberculosis control.

The objective of this study is to assess knowledge and health-seeking practice associated factors toward pulmonary tuberculosis among healthcare workers. The results will help in identifying difficulties and limitations and capacities for enhancement of appropriate interventions for improvement.

\section{Material and Method \\ Study Design, Setting and Population}

This cross sectional study was done among 150 HCWs working in tertiary care centre of Rajasthan. The study was conducted during period of one year from $1^{\text {st }}$ September 2018 to $31^{\text {st }}$ august 2019. Among 150 health care workers, 50 were doctors, 65 were nursing staff and 35 were technical staff.

This study was not submitted for approval of ethical committee, as this study did not involve any risk to participants and only involve study on knowledge, awareness and practice.

\section{Survey design and scoring system}

Data was collected using an anonymous structured questionnaire developed in English. After explaining the survey's purpose and the objectives of the study, the questionnaire was distributed among HCWs and collected the study questionnaires from them once they were filled. The survey was designed to collect Knowledge information concerning TB including TB microbiology and epidemiology, transmission, diagnosis, treatment and infection prevention and control. The questionnaire was developed by reviewing questionnaires in the literature $8,9,10,11$ and the WHO guidelines for TB KAP surveys ${ }^{12}$ but was tailored for the our particular tertiary care centre and the study objectives.

A scoring system was developed to score the KAP responses. Incorrect/inappropriate or uncertain (don't know) responses were given a 0 score, while 1 point was given for choosing the correct/appropriate answer;

Statistical analysis was done using ratio and proportion. Chi square test was used to find significance of knowledge about TB among male and female patients. 


\section{Result}

Characteristics of study participants

The total number of respondents was 150,75 were doctors, 50 were nursing staff and 25 were technician.
Study population consisting of $66.66 \%$ male and $33.33 \%$ female. All participants were over 15 years old and more than half of them $(65.32 \%)$ were within 30-50 years. About 96\% were residing in rural areas.

\section{Knowledge of patients regarding TB}

Table 1: significant difference in knowledge about TB was found between male and female respondents

\begin{tabular}{|l|c|c|c|}
\hline AGE & MALE (100) & FEMALE (50) & PERCENTAGE $(\%)$ \\
\hline$<30$ & 15 & 10 & 16.66 \\
\hline $30-49$ & 35 & 23 & 38.66 \\
\hline $40-49$ & 29 & 11 & 26.66 \\
\hline$>49$ & 21 & 6 & 18.02 \\
\hline Total & 100 & 50 & 100 \\
\hline
\end{tabular}

Most of the patients belong to $30-49$ years (38.66\%) with $35 \%$ males and $23 \%$ of female in this category.

TABLE 2: Knowledge about tuberculosis

\begin{tabular}{|l|c|c|c|}
\hline & Doctors (75) & Nursing staff (50) & Technical staff (25) \\
\hline \multicolumn{3}{|l|}{ Is pulmonary tuberculosis contagious } \\
\hline Yes & 75 & 45 & 20 \\
\hline No & 0 & 5 & 5 \\
\hline Is there a causative agent of tuberculosis? & 47 \\
\hline Yes & 75 & 3 & 23 \\
\hline No & 0 & 3 & 2 \\
\hline Environmental factors contributes in tuberculosis \\
\hline Yes & 75 & 46 & 15 \\
\hline No & 0 & 4 & 5 \\
\hline If comorbid conditions affect tuberculosis infection \\
\hline Yes & 74 & 40 & 15 \\
\hline No & 1 & 10 & 10 \\
\hline
\end{tabular}

Figure 1: Knowledge about tuberculosis in healthcare workers

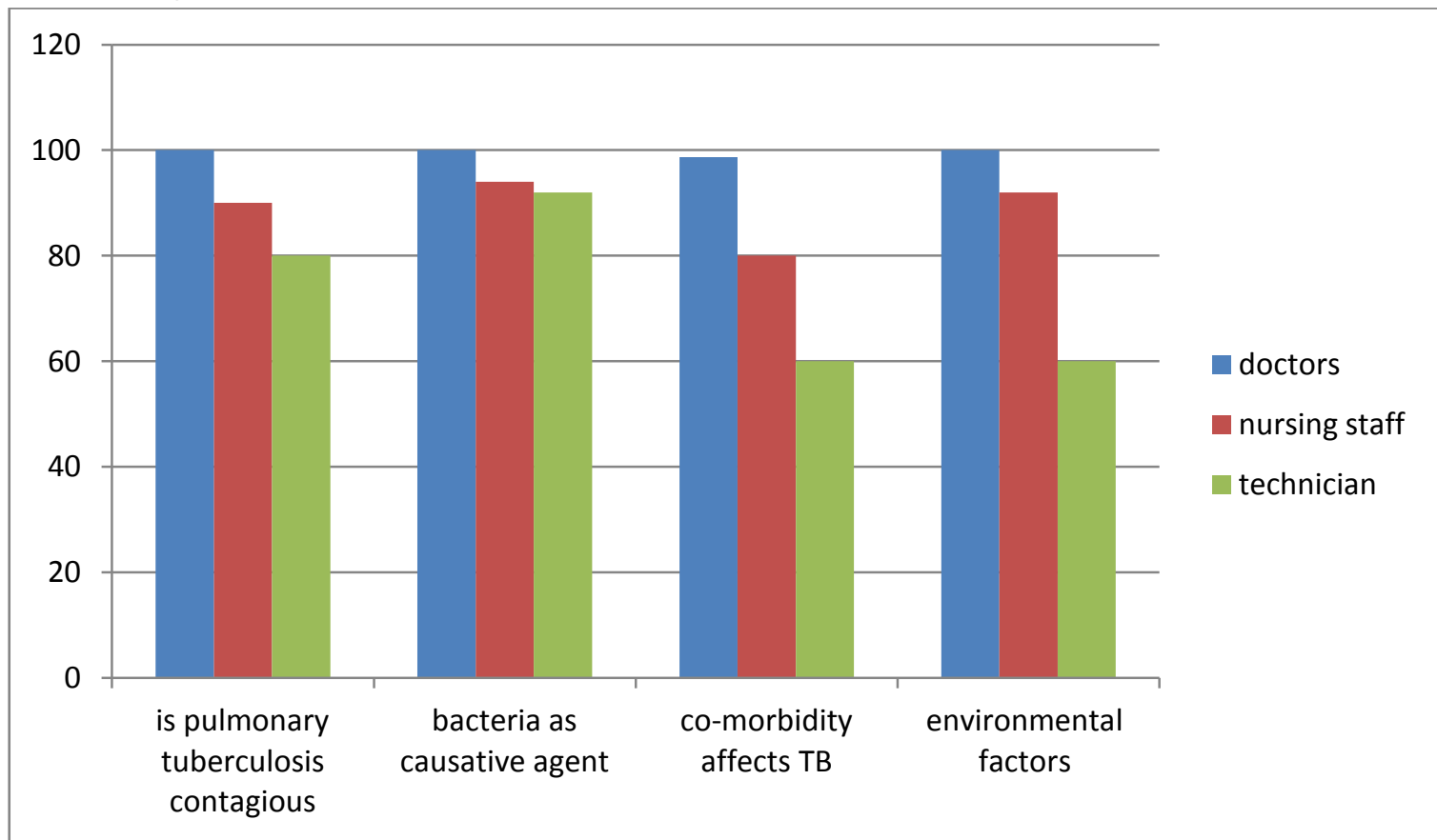


Among 150 healthcare workers, doctors were well aware of tuberculosis, but knowledge of nurses and technicians were slightly lacking. Although $90 \%$ and $80 \%$ of nursing staff and technicians respectively knew that pulmonary tuberculosis is contagious. Overcrowding was considered as major risk factor as environmental factor. Hypertension was considered as most important risk factor although technicians $(60 \%)$ were least to know about it. All were aware that bacteria is causative agent of tuberculosis $\mathrm{m}$ doctors (1005, nursing staff $(80 \%)$ and technicians $(60 \%)$.

Table 3: Knowledge regarding causative agent of tuberculosis

\begin{tabular}{|l|c|c|c|}
\hline Causative agent & Doctors (75) & Nursing staff (50) & Technical staff (25) \\
\hline Bacteria & 65 & 32 & 14 \\
\hline Protozoa & 7 & 10 & 8 \\
\hline Viruses & 3 & 6 & 1 \\
\hline No causative agents & 0 & 2 & 2 \\
\hline
\end{tabular}

Table 4: Knowledge regarding environmental factors in pulmonary tuberculosis

\begin{tabular}{|l|c|c|c|}
\hline Factors & Doctors (75) & Nursing staff(50) & Technical staff (25) \\
\hline Illiteracy & 12 & 8 & 2 \\
\hline Overcrowding & 45 & 25 & 12 \\
\hline Poverty & 10 & 9 & 7 \\
\hline Unemployment & 8 & 8 & 4 \\
\hline
\end{tabular}

Table 5 Knowledge regarding co morbid conditions responsible for pulmonary tuberculosis infection

\begin{tabular}{|l|c|c|c|}
\hline Co morbid conditions & Doctors (75) & Nursing staff (50) & Technician (25) \\
\hline Chronic alcoholism & 4 & 10 & 4 \\
\hline HIV & 12 & 9 & 3 \\
\hline Hypertension & 55 & 25 & 15 \\
\hline Diabetes mellitus & 4 & 6 & 3 \\
\hline
\end{tabular}

Table 6 Knowledge regarding clinical presentation and diagnosis of tuberculosis $(n=150)$

\begin{tabular}{|l|c|c|c|}
\hline & Doctors (75) & Nursing staff (50) & Technician (25) \\
\hline Symptoms of tuberculosis & 50 & 30 & 10 \\
\hline 2 weeks cough & 5 & 2 & 4 \\
\hline Diarrhea & 8 & 10 & 8 \\
\hline Evening rise of temperature & 12 & 8 & 3 \\
\hline Weight loss & \multicolumn{3}{|l|}{} \\
\hline Areas affected by tuberculosis & 15 & 8 & 2 \\
\hline Cervical lymphnode & 10 & 7 & 3 \\
\hline Intestine & 5 & 5 & 1 \\
\hline Nails & 45 & 30 & 19 \\
\hline Lungs & 60 & 35 & 15 \\
\hline Diagnosis of pulmonary tuberculosis is by which sample & 3 \\
\hline Sputum & 1 & 5 & 1 \\
\hline Urine & 10 & 1 & 6 \\
\hline BAL & 4 & 9 & 23 \\
\hline Blood & \multicolumn{5}{|l|}{} \\
\hline Role of chest x-ray in diagnosis & \multicolumn{3}{|l|}{} \\
\hline Yes & 70 & 48 & 2 \\
\hline No & 5 & 2 & 20 \\
\hline Screening of HIV needed in a Patient of tuberculosis \\
\hline Yes & 73 & 23 & \\
\hline No & 2 & 27 & \\
\hline
\end{tabular}


Figure 2: Knowledge regarding clinical presentation of tuberculosis

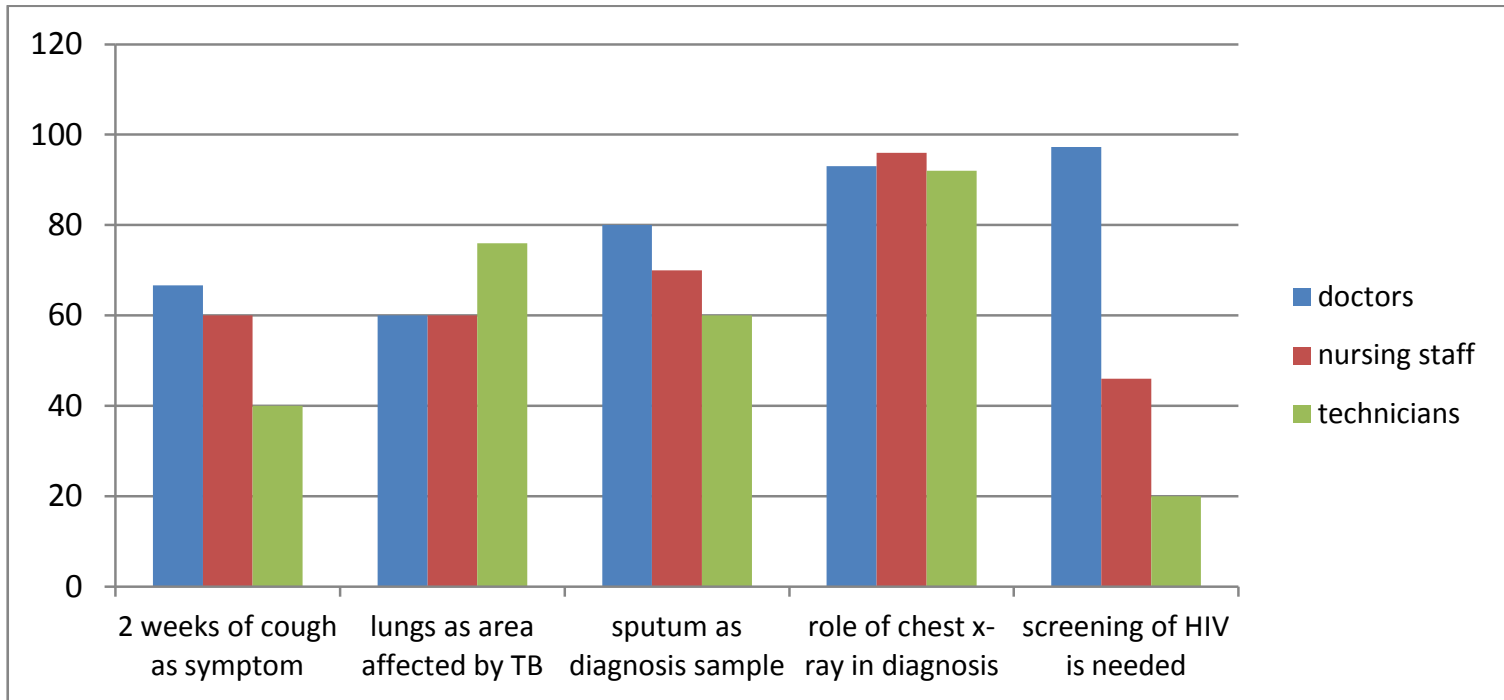

All were aware about clinical presentation of tuberculosis, but only $20 \%$ technician and $46 \%$ nursing staff were aware that HIV screening was needed in tuberculosis patients.

Table 7: Knowledge regarding treatment of tuberculosis

\begin{tabular}{|c|c|c|c|}
\hline & Doctors (75) & Nursing staff (50) & Technician (25) \\
\hline \multicolumn{4}{|c|}{ Complete and free cure possible? } \\
\hline Yes & 70 & 40 & 15 \\
\hline No & 5 & 10 & 10 \\
\hline \multicolumn{4}{|l|}{ Duration of treatment } \\
\hline Six weeks & 0 & 5 & 5 \\
\hline Six months & 70 & 25 & 10 \\
\hline Two months & 0 & 5 & 3 \\
\hline Nine months & 5 & 10 & 7 \\
\hline \multicolumn{4}{|l|}{ What is MDR } \\
\hline Mono dose response & 0 & 10 & 10 \\
\hline Mini dose response & 0 & 10 & 5 \\
\hline multi drug resistance & 75 & 30 & 10 \\
\hline \multicolumn{4}{|c|}{ ATT can be taken during pregnancy } \\
\hline Yes & 70 & 25 & 15 \\
\hline No & 5 & 25 & 10 \\
\hline
\end{tabular}

Figure 3: Knowledge regarding treatment of tuberculosis

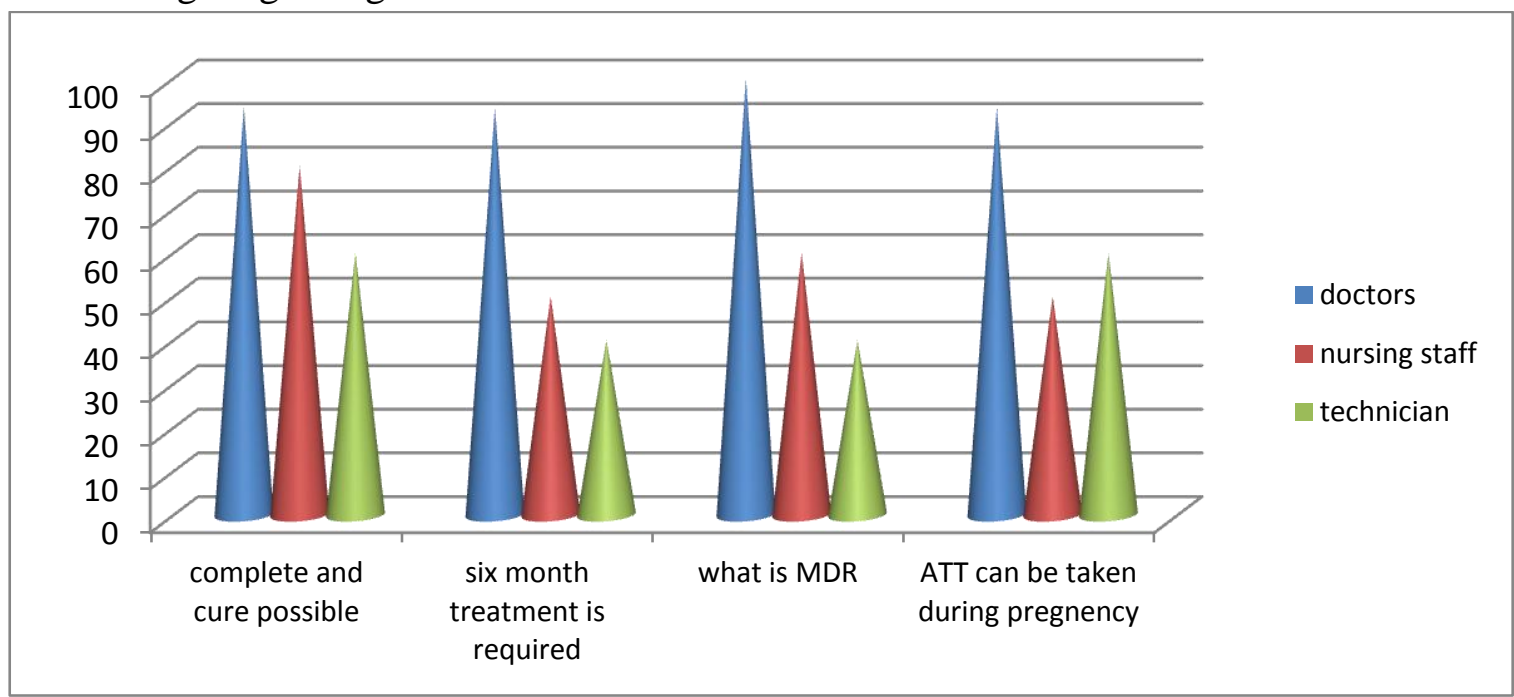

All doctors were aware about treatment of tuberculosis. $40 \%$ technicians and 50\% nursing staff knew about six month course for tuberculosis. Technicians (40\%) and nursing staff (60\%) were aware about MDR. 
Table 8: Knowledge regarding mode of transmission and prevention of tuberculosis

\begin{tabular}{|c|c|c|c|}
\hline & Doctors (75) & $\begin{array}{l}\text { Nursing } \\
\text { staff(50) }\end{array}$ & Technician (25) \\
\hline \multicolumn{4}{|l|}{ Mode of transmission } \\
\hline Insect borne & 0 & 10 & 10 \\
\hline Air borne & 75 & 20 & 5 \\
\hline Water borne & 0 & 10 & 5 \\
\hline Food borne & 0 & 10 & 5 \\
\hline \multicolumn{4}{|c|}{ Advise to family members of patient } \\
\hline Isolate the patient & 10 & 35 & 20 \\
\hline $\begin{array}{l}\text { Encourage patient to use } \\
\text { personal protective measures }\end{array}$ & 65 & 15 & 5 \\
\hline \multicolumn{4}{|c|}{ Is green mask helpful in preventing tuberculosis in health care worker } \\
\hline Yes & 5 & 5 & 2 \\
\hline No & 70 & 45 & 20 \\
\hline \multicolumn{4}{|c|}{ Breast feeding spreads tuberculosis } \\
\hline yes & 5 & 15 & 20 \\
\hline no & 70 & 35 & 5 \\
\hline \multicolumn{4}{|c|}{ Can it be spread by shaking hands } \\
\hline Yes & 4 & 35 & 20 \\
\hline No & 71 & 15 & 5 \\
\hline \multicolumn{4}{|l|}{ Is tuberculosis preventable } \\
\hline Yes & 70 & 30 & 10 \\
\hline no & 5 & 20 & 15 \\
\hline
\end{tabular}

Figure 4: Knowledge regarding mode of transmission and prevention

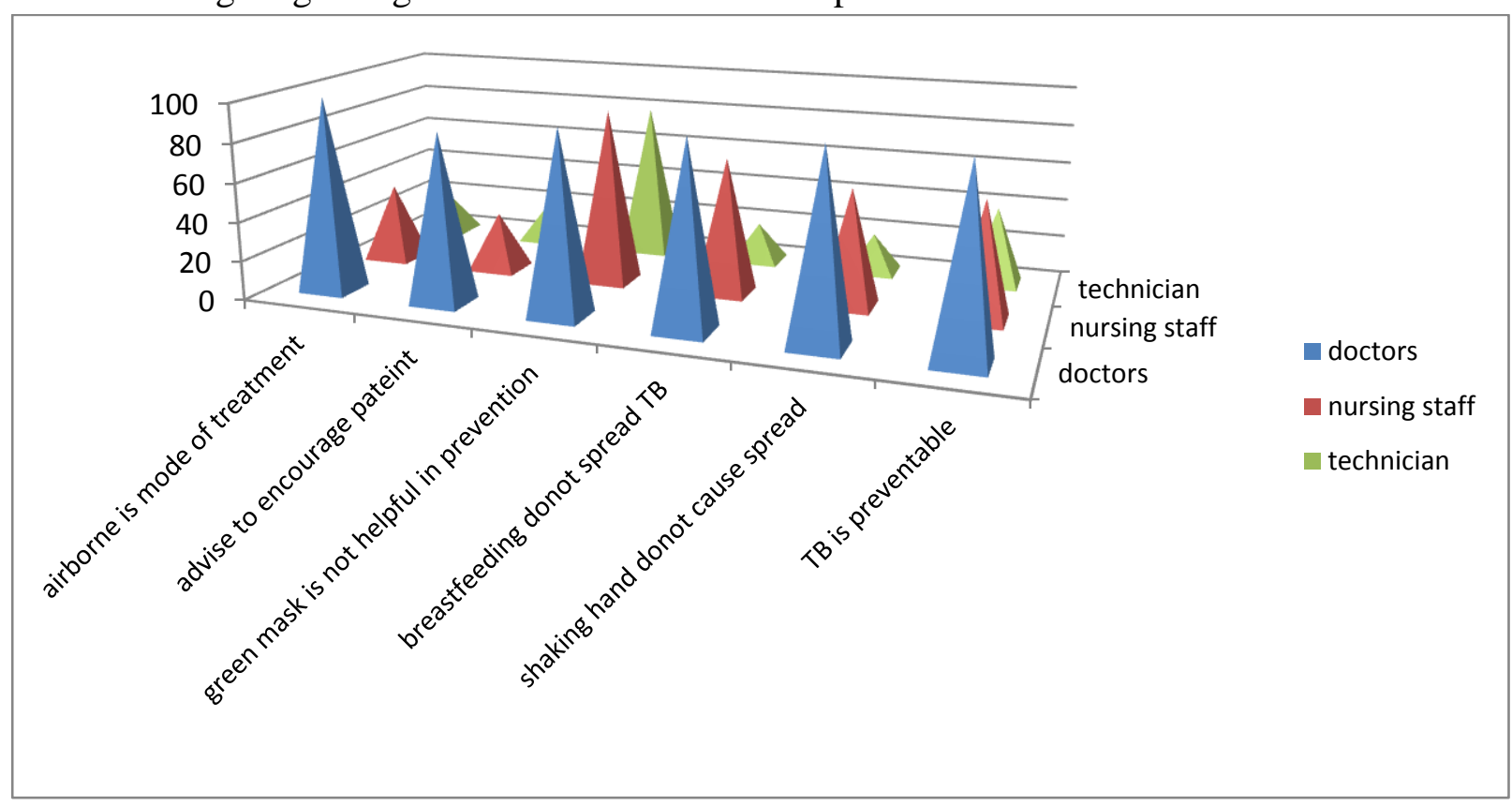

When knowledge regarding mode of transmission was assessed then $93.33 \%$ doctors were aware about it. Technicians (20\%) and nursing staff (70\%) were aware that breastfeeding does not spread tuberculosis and it is not spreads by hand shaking. $20 \%$ technicians and 30\% nursing staff advised family members to isolate there patients.
Table 9: Distribution of study cases according to demographic area $(n=150)$

\begin{tabular}{|l|c|c|}
\hline & Rural & Urban \\
\hline Doctors (75) & 30 & 45 \\
\hline Nursing staff (50) & 49 & 1 \\
\hline Technical staff (25) & 22 & 3 \\
\hline Total & 101 & 49 \\
\hline
\end{tabular}

$67.33 \%$ of healthcare workers were of rural area , out of which $88 \%$ are technicians and $98 \%$ are nursing staff. $60 \%$ of doctors belong to urban area. 


\section{Discussion}

This study was done on 150 health care workers including doctors, nursing staff and technicians to access knowledge, attitude and practice towards tuberculosis.

Majority of participants (74\%) showed bacteria as causative agent of tuberculosis. Our study showed a higher proportion of the participants (93\%) were aware of contagious nature of pulmonary tuberculosis which is similar to study done by Acharya et $\mathrm{al}^{13}$. Overcrowding was mentioned by majority of HCWs as method of transmission. Co-morbid conditions which are highly associated with tuberculosis were correctly identified as hypertension (963\%) as major cause followed by chronic alcoholism (14\%) and least as Diabetes mellitus (8\%).

Knowledge regarding clinical presentation and diagnosis of tuberculosis, HCWs correctly mentioned that cough more than 2 weeks $(60 \%)$ as major criteria followed by evening rise of temperature $(17.3 \%)$ and least as diarrhea $(7 \%)$.

On analyzing of knowledge, $83.3 \%$ of $\mathrm{HCWs}$ knew that tuberculosis is curable and free cure is available for this disease. Most of them correctly knew $(95 \%)$ that duration of treatment is six months. $76 \%$ of them knew the correct term of MDR and $73 \%$ of them knew that ATT can be taken during pregnancy.

On analyzing data on knowledge regarding transmission and prevention of tuberculosis, $66.6 \%$ of HCWs were aware that it is air borne disease. $73.33 \%$ of participants knew that tuberculosis is preventable and $86 \%$ stated that green surgical mask could not provide protection against tuberculosis. High level of awareness was observed regarding tuberculosis transmission from breast feeding and shaking hands. 91\% and $73.33 \%$ of participants knew that shaking hands and breast feeding respectively causes tuberculosis .

In various studies conducted in African countries, showed the dual burden of HIV infection and tuberculosis, due to limited capacity of healthcare workers in diagnosis and management of tuberculosis. There are gaps in knowledge and skills regarding tuberculosis which should be studied and addressed continuously through professional development programmes ${ }^{14}$. But factors like limited access to programs, financial problems, poor infrastructure and mismatch between educational needs and implemented programs causes these gaps not to fill. Therefore there is a dire need to fill these gaps if we need to improve outcome of tuberculosis ${ }^{15}$.

Health care workers are at increased risk of infection from tuberculosis. Various Studies reported that the knowledge regarding preventive measures, screening and treatment rates were found to be low among them ${ }^{16 ., 17}$. A study done on nursing staff who were involved in management of patients suffering from tuberculosis by Cabral V.K. et al ${ }^{19}$ showed that distance learning course resulted in significant improvement in knowledge regarding the same.

A review done by $\mathrm{Wu} \mathrm{S}$. et $\mathrm{al}^{20}$ showed that most studies which were done only assess the acquisition of knowledge, but the domain of behavior change is less assessed. A positive attitude and proper knowledge is needed regarding infection control practice of tuberculosis. ${ }^{21}$ Another study done showed that lack of social support acts as a environmental barrier for control of Tuberculosis. Therefore community participation and proper involvement of health care workers are essential to control infection of tuberculosis $^{22}$. Factors like lack of knowledge, community skills and poor interpersonal relationship among healthcare workers causes negative effect on well being of patients who are on long term therapy with anti tubercular drugs ${ }^{23}$. Nursing professionals have a crucial role in tuberculosis management as they take care of patients suffering from tuberculosis and also supervise DOTS distribution. Improving awareness on knowledge in preventive and curative care helps in better management of patient, this can be achieved through clinical experience and continuing professional education $^{24,25}$. 
Study conducted in Northern Israel reported that health care workers have a low rate to be screened using purified protein derivatives for tuberculosis despite them educating regarding importance of screening $^{18}$.

\section{Conclusion}

In conclusion, after assessing data doctors are well aware of knowledge regarding tuberculosis, but nursing staff and technicians lack sufficient knowledge . They are still in need of continuing programs to educate them regarding control and prevention of this disease. Initiative should be taken in each and every hospital to start RNTCP sensitization program at regular intervals. As 70 $\%$ and $80 \%$ nursing staff and technicians respectively believed in isolation of tuberculosis patients, the knowledge about social stigma should be taught to them as they play a major role in care of the patient.

Thus improved knowledge on tuberculosis of healthcare workers will contribute to better management of this disease and will help in long term plan to eradicate tuberculosis from India

\section{References}

1. Mathema B, Kurepina NE, Bifani PJ, Kreiswirth BN. Molecular epidemiology of tuberculosis: current insights. Clin Microbiol Rev. 2006;19:658-85.

2. World Health Organization. Global tuberculosis report 2017. Geneva: 2017

3. Lawn SD, Afful B, Acheampong JW. Pulmonary tuberculosis: diagnostic delay. Int J Tuberc Lung Dis. 2006;4:1190-1. 4. Demissie M, Lindtjorn

4. B, Berhane Y. Patient and health service delay in the diagnosis of pulmonary tuberculosis. BMC Public Health. 2009;2:23.

5. Storla DG, Yimer S, Bjune GA. A systematic review of delay in the diagnosis and treatment of tuberculosis. BMC Public Health. 2008;8:15.
6. Jurcev Savicevic A1, Popovic-Grle S, Milovac S, Ivcevic I, Vukasovic M, Viali $\mathrm{V}$, et al. Tuberculosis knowledge among patients in out-patient settings. Int $\mathbf{J}$ Tuberc Lung Dis. 2008;12:780-5.

7. Mesfin MM, Tasew TW, Tareke IG, Mulugeta GWM, Richard MJ, et al. Knowledge Attitude and Practice on pulmonary tuberculosis and their choice of treatment supervisor. Ethiop J Health Dev. 2005;19:21-7.

8. Temesgen C. Knowledge and practice of tuberculosis infection control among health professionals in Bahir Dar, West and East Gojjam zone Hospital; Northwest Ethiopia. BMC Health Serv Res. 2011;14:593.

9. Malangu N, Adebanjo OD. Knowledge and practices about multidrug-resistant tuberculosis amongst healthcare workers in Maseru. Afr J Prim Health Care Fam Med. 2015;7(1). Epub 2015/08/08. 10.4102/phcfm.v7i1.774

10. Bhebhe LT, Van Rooyen C, Steinberg WJ. Attitudes, knowledge and practices of healthcare workers regarding occupational exposure of pulmonary tuberculosis. Afr $\mathbf{J}$ Prim Health Care Fam Med. 2014;6(1):E1-6. Epub 2014/01/01. 10.4102/phcfm.v6i1.597

11. Kanjee Z, Catterick K, Moll AP, Amico KR, Friedland GH. Tuberculosis infection control in rural South Africa: survey of knowledge, attitude and practice in hospital staff. J Hosp Infect. 2011;79(4):333-8. Epub 2011/10/08. 10.1016/j.jhin.2011.06.017 .

12. World Health Organization. Advocacy, communication and social mobilization for TB control: A guide to developing knowledge, attitude and practice surveys. Geneva, Switzerland: 2008.

13. Acharya Pr, D'Souza M, Sahoo RC. Tuberculosis knowledge and attitude in aspiring doctors and nurses- Is it time for 
our TB teaching methods to evolve? Indian J Tuberc,2017;64(1):20-5.

14. Feldacker C, Jacob S, Chung MH, Nartker A, Kim HN. Experiences and perceptions of online continuing professional development among clinicians in subsaharan Africa. Hum resour health, 2017; 15(1):89.

15. Feldacker c, Jacob $\mathrm{S}$, chung $\mathrm{MH}$, Nartker A, Kim HN. Experiences and perceptions of online continuing professional development among clinicians in subsaharan Africa. Hum resour health,2017; 15(1):89.

16. Pathak V, Harrington Z, Dobler CC. Attitudes towars preventive tuberculosis treatment among hospital staff. Peer J,2016;4:e1738.

17. Mirtskhulava V, Whitaker JA, Kipiani M, Harris DA, Tabagari N, Owen-smith AA, et al. Determinants of tuberculosis infection control-related behaviors among healthcare workers in the country of Georgia. Infect control Hosp Epidemiol, 2015;36(5):522-8.

18. Taubman D, Titler N, Edelstein H, Elias M, Saliba W. Providing detailed information about latent tuberculosis and compliance with the PPD test among healthcare workers in Israel: a randomized controlled study. J Epidemiol Glob Health,2013;3(4):253-60.

19. Cabral VK,Valentini DF, Jr., Rocha MVV, de Almeida CPB, Cazella SC, Silva DR. Distance learning course for healthcare professionals: continuing education in tuberculosis. Telemed J E Health, 2017; 23(12) : 996-1001.

20. $\mathrm{Wu}$ S, Roychowdhury I, Khan M. Evaluating the impact of healthcare provider training to improve tuberculosis management: a systemic review of methods and outcome indicators used. Int $\mathbf{J}$ infect Dis, 2017; 56: 105-10.

21. Engelbrecht M, Janse van Rensburg A, Kigozi G, van Rensburg HD. Factors associated with good TB infection control practices among primary healthcare workers in the free state province, south Africa. BMC Infect Dis. 2016;16(1) :633.

22. Mabunda JT, Khoza LB, Van den Borne HB, Lebese RT. Needs assessment for adapting TB directly observed treatment intervention programme in Limpopo Province, south Africa : A community based participatory research approach. Afr J Prim Health Care Fam Med,2016; 8(2):e1-7.

23. Ibrahim LM, Hadjia IS, Nguku P, Waziri NE, akhimien MO, Patrobas P, et al. health care workers knowledge and attitude towards TB patients under direct observation of treatment in plateau state Nigeria,2011. Pan Afr Med J,2014;18 Suppl 1:8.

24. Nagata Y, Kato T. Expanding the role of the nursing profession in tuberculosis medical services. Kekkaku, 2013;88 (12): 815-25.

25. Yukselturk N, Dinc L. Knowledge about anti-tuberculosis treatment among nurses at tuberculosis clinics. Int $\mathbf{J}$ nurs Pract, 2013;19(1) :47-53. 